\title{
Helping athletes affected by sexual violence: my challenge to the sports and exercise medicine community
}

\section{MY CHILDHOOD STORY}

If you saw me in clinic as a young kid, you would almost certainly describe me as healthy, active, energetic and high achieving. I wore a smile as wide as my face and talked excitedly about my friends, sports and summer plans whenever asked. What you wouldn't know about me was that in third grade, I was raped by a member of my extended family; and throughout middle and high school, I was sexually and emotionally abused by an alcoholic parent. You would not know this as a clinician because I always wore an impenetrable shield in order to get through my visit with you. My smile and kindness served as a mask to hide what I felt were the shameful, dark parts of me, and my costume always included some combination of athletic clothes and sports equipment.

Contrary to many recent high-profile cases, ${ }^{1}$ I was not subjected to sexual violence in sport. Yet sport was fully enmeshed in my experiences of sexual violence. Beyond the genuine joy and happiness I felt while playing sports, they provided me a necessary sense of safety and belonging outside my home and important safety from my unrelenting shame and fear. Simply put: sports saved my life.

\section{MY CHALLENGING EXPERIENCES WITH CLINICIANS}

The summer before ninth grade, at a time when I was actively experiencing abuse, I visited my paediatrician for a preparticipation sports examination. My physician noted that I had lost a significant amount of weight since my last physical. I had never been preoccupied with my weight, but he accused me of restricting food and suggested treatment for anorexia. This was not the issue, but my truth was not important to him. He had convinced himself that he knew my struggle without even giving me the opportunity to speak my truth.

During my junior soccer season in college, after a bout with bronchitis, I found myself struggling to breathe during exercise. I met with multiple doctors and underwent numerous tests. The tests always came back negative and were often accompanied with 'there is nothing I can do for you' or 'maybe it's time to stop playing sports'. Still sidelined, my athletic trainer encouraged me to visit one more specialist who listened carefully to my symptoms and ultimately diagnosed me with exercise-induced asthma. It was a game-changer. Though grateful for that physician (and my athletic trainer), I never forgot the feeling of being unheard and not believed by those before him.

\section{THE IMPACT OF MY HEALTHCARE EXPERIENCES}

Perhaps the most detrimental aspect of these healthcare encounters was that they reinforced my negative beliefs: that my experiences did not matter, that my voice did not matter. Trust is a central component to any clinician-patient relationship, and the ability to trust is also a major hurdle for those affected by sexual violence. To this day, I struggle seeing clinicians-not because I believe their intentions are not good or that they will harm me, but because I fear not being heard when I truly need help. I fear my pain or ailment may not be worthy of their care.

Patients affected by sexual violence are skilled at scanning their environments to assess their safety. Fair or not, these patients will judge a clinician's reaction (or lack-there-of) to anything they share during a clinic visit-no matter how innocuous. Clinician hesitancy or indifference will close a door that may never reopen. As a lifetime athlete, I've spent a lot of time in doctors' offices. Yet no physician has asked me if I have a history of sexual violence-and in the rare occasions when a nurse or medical assistant has inquired about a history of trauma, it has always been in the same, uninterested breath as when screening me for known allergies to latex or medications. I've never answered 'yes' to that question.
Box 1 My suggestions for clinicians when talking about sexual violence with an athlete

When to ask about sexual violence

- At all initial athlete/patient visits.

- If associated conditions are present (eg, anxiety, depression, body dysmorphia, disordered eating, suicidality/suicidal ideation).

How to ask about sexual violence

- Be kind, empathetic and fully interested.

- Limit distractions (eg, move away from the computer) and be fully engaged.

- Be sure to be on the same level as the athlete (ie, seated if possible).

- Provide context and ask directly. For example: 'Sexual abuse is more common than we would like to believe. I worry about the effects it can have on individuals and make a point to talk about it with all my athletes so I am better able to help them. Have you ever experienced any degree of sexual violence?'

- Do not try to force a disclosure, even if you suspect a history of sexual violence. Instead, stay connected and let the athlete know you are on their team, care about their well-being, and revisit the topic again in the future.

How to respond to a disclosure of sexual violence

- Support and validate (eg, 'Thank you for trusting me', 'I believe you', 'I may not have all the answers, but we will work through this together', 'I will support you').

- Avoid physical touch (eg, hug, hand on shoulder) - instead, stay emotionally and conversationally connected

- Do not ask probing questions about the event(s) itself; instead inquire about the athlete's current feelings/discomfort regarding what they just shared, their well-being, and ability to cope during everyday life.

How to provide ongoing support for athletes affected by sexual violence

- Give your athlete references for appropriate health professionals with contact information and offer to help schedule the first appointment. This first step will be difficult for many affected athletes.

- After the initial disclosure, follow-up briefly with the patient (perhaps regarding the first visit with a counsellor) to demonstrate care and trust and reassure the athlete that you are there to support them. 


\section{MY CALL TO CLINICIANS}

I often wonder if my struggles today would be different if just one adult-one coach, teacher, parent or clinician-had found a way to see through my mask and costume, to understand my cries for help, and to ask me if I was okay. My pleas were often quiet, but they were there. While I do not blame anyone for my 15 years of silence, I do believe clinicians can do better. The sports and exercise medicine community in particular has the ability to profoundly and positively impact the lives of affected athletes. But it will not be enough to rely on safeguards, policies and educational tools. Awareness and education alone will not eradicate sexual violence. Abuse will happen and healing will be needed. Optimal healing requires a commitment from all clinicians to be willing to connect with patients in new and vulnerable ways.

Providing care and support for those affected by sexual violence is not straightforward or easy (box 1); and there is no algorithm for treating sexual violence. Yet, I urge clinicians not to allow uncertainty and unease to be the reason you avoid asking the questions. Your athlete may be desperately seeking someone who can help, though unable to ask for it. And if they don't share on the first, second or third visit, yet you suspect deeper pain or hurt, please do not give up on them. Do not take a negative answer as permission to not address the topic again. Instead, continue to build trust in other ways so they know you are a person with whom they can share if and when they feel ready.

Silence, fear and inaction fuel the cycle of sexual violence, but authentic conversation, care and connection disrupt its bonds. Sports clinicians are in a unique position to help break this vicious cycle, but if you are unable or unwilling to connect with the athlete and share a small amount of their burden (sexual violence or otherwise), then your ability to truly help them heal is greatly diminished. Only when an athlete believes that their story is important, and that they are important, can their healing begin.
Acknowledgements I am deeply grateful for the support of a colleague who encouraged me to share this message, assuring me it would benefit those willing and able to hear it.

Contributors This author is the sole contributor to all aspects of this piece and wished to remain anonymous.

Funding The author has not declared a specific grant for this research from any funding agency in the public, commercial or not-for-profit sectors.

Competing interests None declared.

Patient consent for publication Not required.

Provenance and peer review Not commissioned; internally peer reviewed.

(c) Author(s) (or their employer(s)) 2021. No commercial re-use. See rights and permissions. Published by BMJ.

\section{A Check for updates}

To cite Br J Sports Med 2021;55:177-178.

Accepted 7 October 2020

Published Online First 5 November 2020

Br J Sports Med 2021:55:177-178.

doi:10.1136/bjsports-2020-103301

\section{REFERENCE}

1 The Associated Press. Sports impacted by sexual abuse, 2018. Available: https://apnews.com/article/709ed3b6 72ee498c86bb1bf05ce61d19 